\title{
Technical Note: Comparison of three bullet recovery systems
}

\author{
Denis Werner ${ }^{1 *}$, Damien Rhumorbarbe ${ }^{1}$, Peter Kronseder ${ }^{2}$, Alain Gallusser ${ }^{1}$. \\ ${ }^{I}$ Ecole des sciences criminelles, Université de Lausanne, Bâtiment Batochime, 1015 Lausanne-Dorigny, Switzerland. \\ ${ }^{2}$ Rubinum Engineering GmbH, Lise-Meitner-Strasse 3A, 82024 Taufkirchen, Germany. \\ * Corresponding author (e-mail: denis.werner@unil.ch).
}

\begin{abstract}
Comparing the marks left on questioned bullets to those left on reference bullets is the main aim of a firearm identification expertise. Thus, producing reference bullets with a questioned firearm is an essential step. Different kinds of system have been developed to safely recover bullets fired from questioned firearms. However, the performance of each system and its impact on traces left on the bullets have not been addressed.

Three bullet recovery systems - a horizontal water tank, a cotton tube and a recently designed fleece - were used to fire seven types of ammunition of various type, shape and casing. The bullets were then described and images of their surface were acquired with an automatic system to study the impact of each system on the bullets.

The water tank is the more efficient system in terms of quality of the marks. However, it cannot be used to fire every type of ammunition. Some of them, such those used by law enforcement, tend to be damaged with this system. A way to mitigate the problem is to use the cotton or the fleece-based systems, the latter being more universal. It requires a cleaning step to remove all the fibres from the surface of the bullet, but the marks left by the weapon are still of interest.
\end{abstract}

Keywords: Firearms identification; Cotton tube; Water tank; Fleece layers.

\section{Highlights}

- The quality of marks depends on the type of ammunition and recovery system.

- The water tank shows some limitations with certain types of bullet.

- The cotton tube and the newly designed Rubinum fleece are polyvalent.

- So far, several systems are needed to recover the wide range of bullets available.

\section{Introduction}

When firearms are involved in a forensic context, the identification of the firearm is usually among the main questions to address. Thus, if a questioned bullet is found on a crime scene and a questioned firearm seized either on the scene or through the following investigation - the next step is to obtain reference material. A testfiring process in controlled conditions is then conducted by discharging the questioned firearm using an ammunition sharing ideally the characteristics of the questioned bullet (i.e. brand, model, weight, casing). Such tests necessarily involve bullet recovery systems. They are devices designed to stop the reference bullets without causing them any damage that might deter the marks examination.

Literature about bullet recovery systems mostly consists in short articles published in specialized journals such as the Association of Firearms and Toolmarks Examiners Journal (AFTE Journal). Some references may also be found in more general forensic related journals. A review of these publications shows that water tank is a very common system to recover test fired bullets. However, these tanks are usually expensive custom-made devices, made by steel factory on request of police forces $[1,2]$. Homemade adjustments are often required to achieve the goal of police forces [3]. In general, water tanks are very useful for small calibres. Larger versions suitable for higher calibres have been developed [4], however the larger the tank the more expensive it is [5]. Vertical versions are also used, implying adjustments $[6,7]$. The use of a polymer water tank, less expensive, has also been reported [8].

Alternatively, systems devised to recover bullets using cotton are also regularly used. The cotton is sometimes soaked in water $[9,10]$ or alternated with Kevlar® to slow down the bullets [11]. Although the systems based on cotton might be easily transportable [12], they are limited to small calibres and precautions are needed to avoid the cotton catching fire. Anecdotal systems are also mentioned in the specialized literature, such as mix of water, sawdust and cotton [13] or water and cornstarch [14]. Earlier references show that a lot of tests were performed before water tanks became common [15]. 
This literature review shows that a variety of techniques are regularly shared by practitioners through specialized journals. However, despite all the adjustments to improve the devices, the publications scarcely address the comparison of different systems, nor the effects on the quality of the traces usually left by the questioned weapon.

The purpose of this study is to compare the performance of three bullets recovery systems. The general aspect of test-fired bullets will be taken into consideration and the influence of each system on the striation left by the barrel will also be explored. Among the tested systems, two are commonly used in practice - water tank and cotton - and the third one is a novel system recently developed.

\section{Methodology}

Seven types of ammunition were discharged and stopped with three different bullet recovery systems. Table 1 summarizes the detailed information of the material. The first recovery system consists in layers of synthetic non-flammable fleece developed by Rubinum Engineering $\mathrm{GmbH}$. The second system is a rectangular horizontal water tank (dimensions: $1.85 \mathrm{x}$ $1.20 \times 0.80$ m filled with 0.9 cubic meter of water) which cannot be used to discharge shoulder weapons firing high initial velocity projectiles. The last one is made of four card boxes filled with cotton, forming a 2 meters canal.

\begin{tabular}{l|l|l|l}
\hline Test & Calibre & Ammunition & Firearm \\
\hline 1 & .22 Long Rifle & Remington, Solid point $(40 \mathrm{gr})$ & Colt Conversion Unit \\
\hline 2 & .22 Long Rifle & Remington, Hollow point $(40 \mathrm{gr})$ & \\
\hline 3 & $9 \mathrm{~mm}$ Luger & Geco, FMJ Tombac $(124 \mathrm{gr})$ & \\
\hline 4 & $9 \mathrm{~mm}$ Luger & Winchester, SXT 9 Hollow point $(147 \mathrm{gr})$ & \\
\hline 5 & $9 \mathrm{~mm}$ Luger & MEN, QD-PEP II/s $(91$ gr $)$ & \\
\hline 6 & $9 \mathrm{~mm}$ Luger & GECO RUAG, Action 4 Sintox forensis $(94 \mathrm{gr})$ & Colt Python \\
\hline 7 & .357 Magnum & Remington, Lead Flat Nose $(158$ gr $)$ & Colt 1911 \\
\hline 8 & .45 ACP & Magtech, FMC (230 gr) & \\
\hline
\end{tabular}

Table 1. Specificities of the ammunition and firearms used for each test.

For reproducibility purposes, three rounds were fired per type of ammunition with each recovery system. For a given ammunition and recovery system, no discrepancy was noted between each of the three rounds. Thus, only one bullet per ammunition and system was subsequently selected, photographed and described to document its general aspect.

The bullet surface was then scanned with the Evofinder® system (ScannBI Technology Europe GmbH, version 6.3.0.152) to study visually the influence of the recovery system in terms of traces left by the weapon used.

\section{Results}

\subsection{Cleaning process}

The bullet is necessarily heated due to the firing process, causing the cotton or the fleece to melt and adhere to the surface of the bullet. As illustrated in Figure 1a, fibres adhering to the surface might interfere with the examination of traces of interest, especially the individual characteristics of these traces. Images produced with an automatic system such as the Evofinder ${ }^{\circledR}$ also shows affected area, which might be mistaken for damages to the bullet surface (see Figure 1b). Consequently, a cleaning step is mandatory when recovering bullets with these systems.

Even if the larger fibres can be removed with a regular cotton tip, the smaller particles are strongly caught in the asperities of the bullet's surface. Thus, the use of an ultrasonic bath is recommended to clean effectively the bullets from the fibres that might deter further examination of the traces left by the firearm. However, precautions need to be taken regarding the time of exposure to avoid detrimental effects [16]. In this study, the ultrasound bath was used for less than 2 minutes with the .22 Long Rifle calibre bullets (tests 1 and 2) and less than 10 minutes for the other bullets (tests 3 to 6 and 8). The cleaning was not necessary for .357 Magnum lead bullets (test 7) since the fibres were not caught on the surface as they were with plated or cased bullets. 

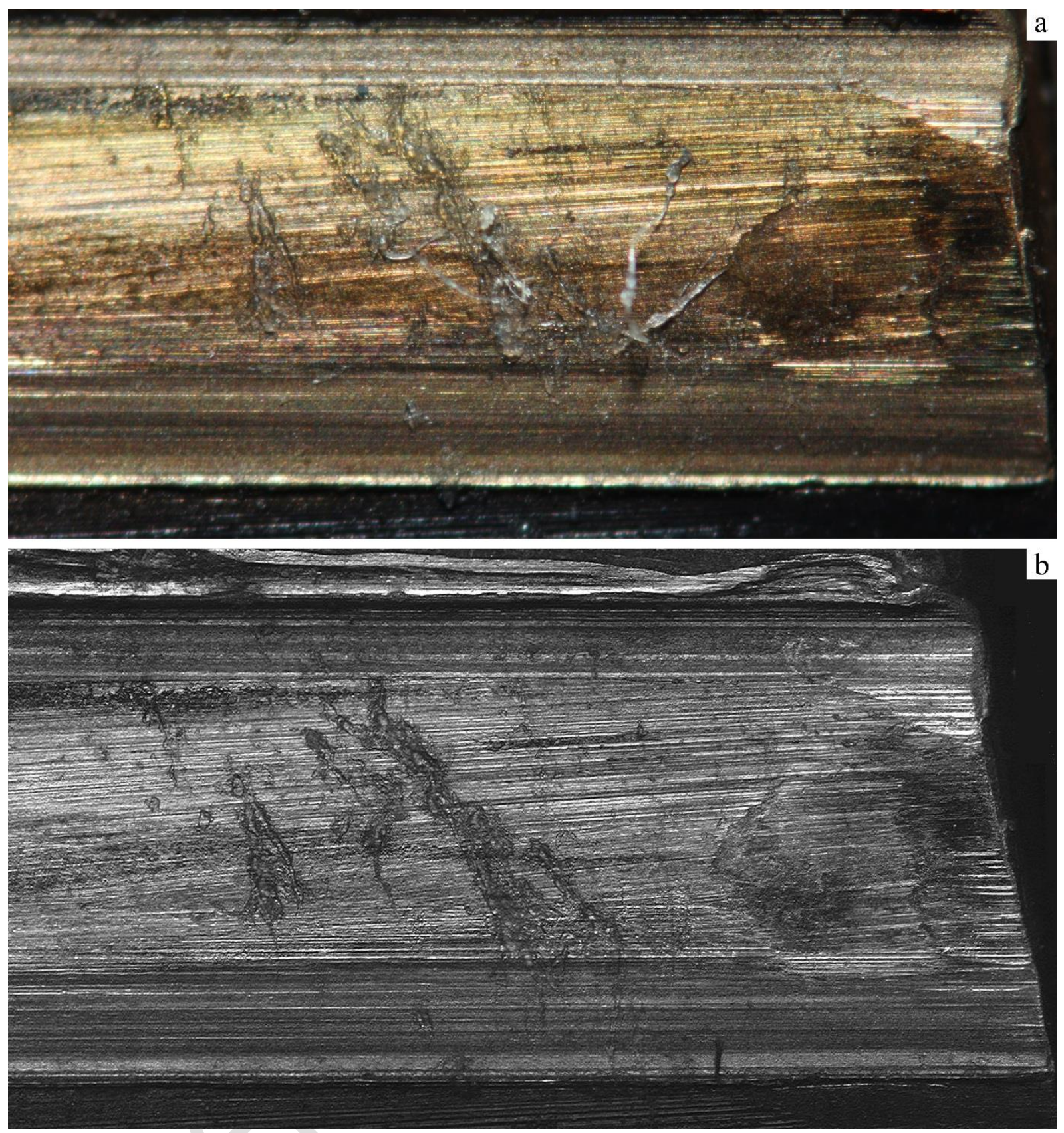

Figure 1. Fibres in a land impression (a) observed under a comparison macroscope and (b) scanned with the Evofinder® system.

\subsection{General description of the bullets}

Figure 2 shows the general aspect of a bullet per type of recovery system and ammunition.

Plated .22 Long Rifle round bullets (test 1) are recovered without any general damage when fired in a water tank. On the contrary, hollow point .22 Long Rifle bullets (test 2) will expand in water. The plated coating is also damaged through the process, which may deter further examination of the marks left by the barrel.

Generally, whatever the system used, FMJ bullets (tests 3 and 8) are less damaged than the other types of bullet when recovered. Except from the typical mark on the top of the bullet due to the contact with the water (test 8), no deformation is noted for these bullets. However, hollow point bullets (test 4) are heavily damaged when fired in a water tank, the casing being severely altered and separated from the lead core. No general damage was noted with the other recovery systems. When .357 Magnum lead bullets (test 7) are recovered in the water tank, the only notable mark is the one on the top of the bullet due to the contact with the water. The Rubinum fleece seems to have abrasive properties, impact the visibility of both land impressions and cannelures. The cotton-based recovery system does not cause any general damage. Deformation bullets (tests 5 and 6) expanded when recovered in the water tank, resulting in the yellow tip of the Action 4 to be separated from the core (test 6). Besides their basis tends to be slightly deformed, compared to bullets recovered with the cotton tube or the Rubinum fleece. It is important to note that the ammunition used for tests 5 and 6 includes controlled deformation bullets as opposed to the hollow point expansion bullets (test 4) which open randomly or sometimes break apart when hitting a target [17-19]. 


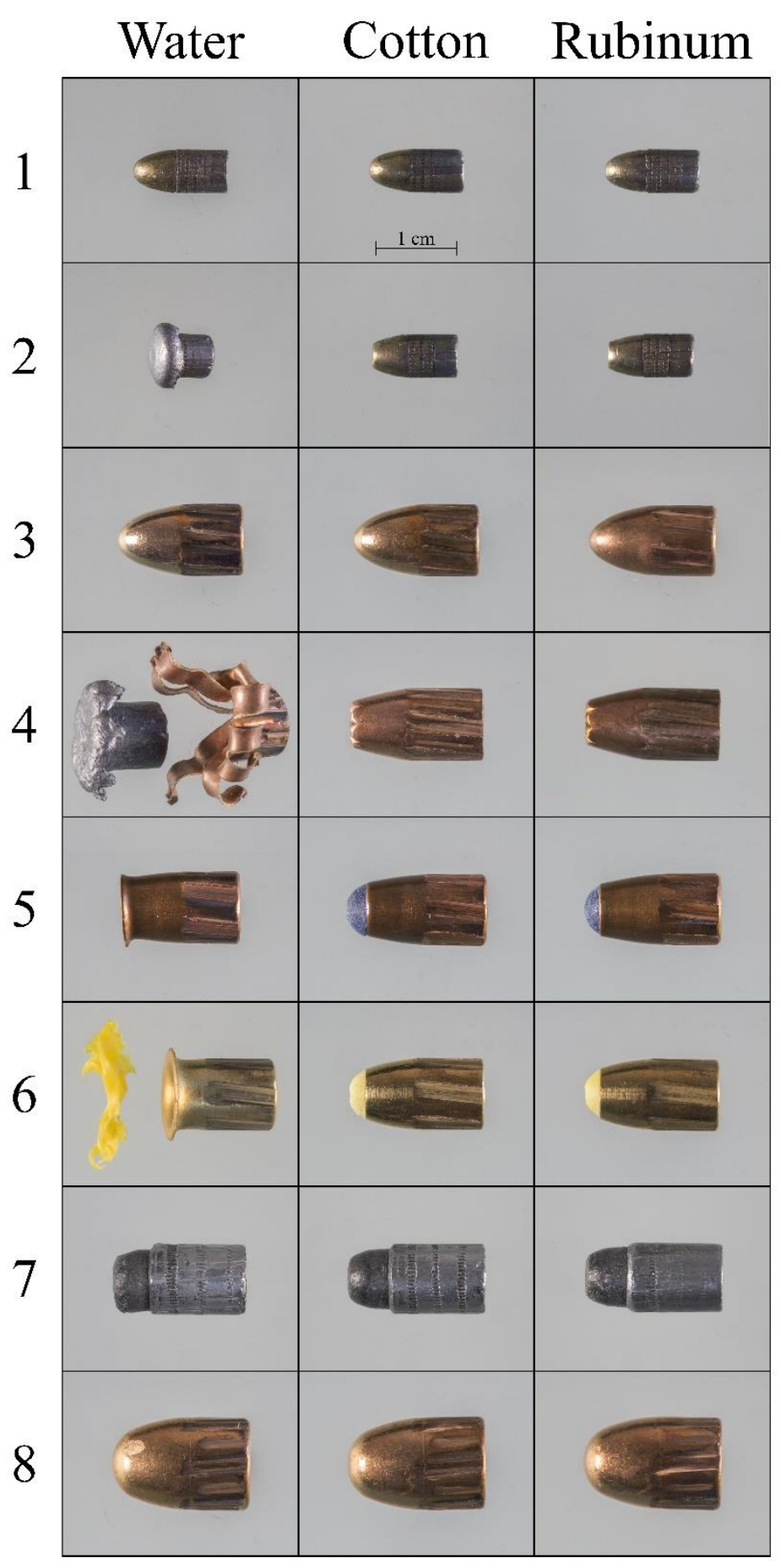

Figure 2. General overview of the bullets recovered with each system.

\subsection{Traces description with Evofinder ${ }^{\circledR}$}

Figure 3 show that the marks left on .22 Long Rifle calibre bullets (tests 1 and 2) recovered with the cotton tube and the Rubinum fleece are of lesser quality than on the one recovered with the water tank. The marks left by the barrel tend to be erased by the abrasive property of the recovery systems. Besides, the plated coating of the bullet might by damaged during the cleaning process with the ultrasound bath. The effect is rather important with the cotton based recovery system, and even more with the Rubinum fleece. On the other hand, the marks on land and grooves impressions are better when the bullets are recovered with the water tank, despite the deformation of the .22 Long Rifle hollow point bullet (test 2). As shown in Figure 4, the abrasive effect is also extremely present on lead bullets (test 7) with the Rubinum fleece and, to a lesser extent, with the cotton tube. The land impressions have a better definition when the bullets are recovered in the water tank and the cotton tube, even if only a few striae would be suitable for an expertise. Indeed, comparing striation left by a barrel on lead bullets is challenging due to the nature of the surface - the lead being softer that the casing materials. Consequently, except 
for general descriptions, assessing the performance of recovery systems with lead bullets might be difficult, since these bullets might not initially bear any striation.
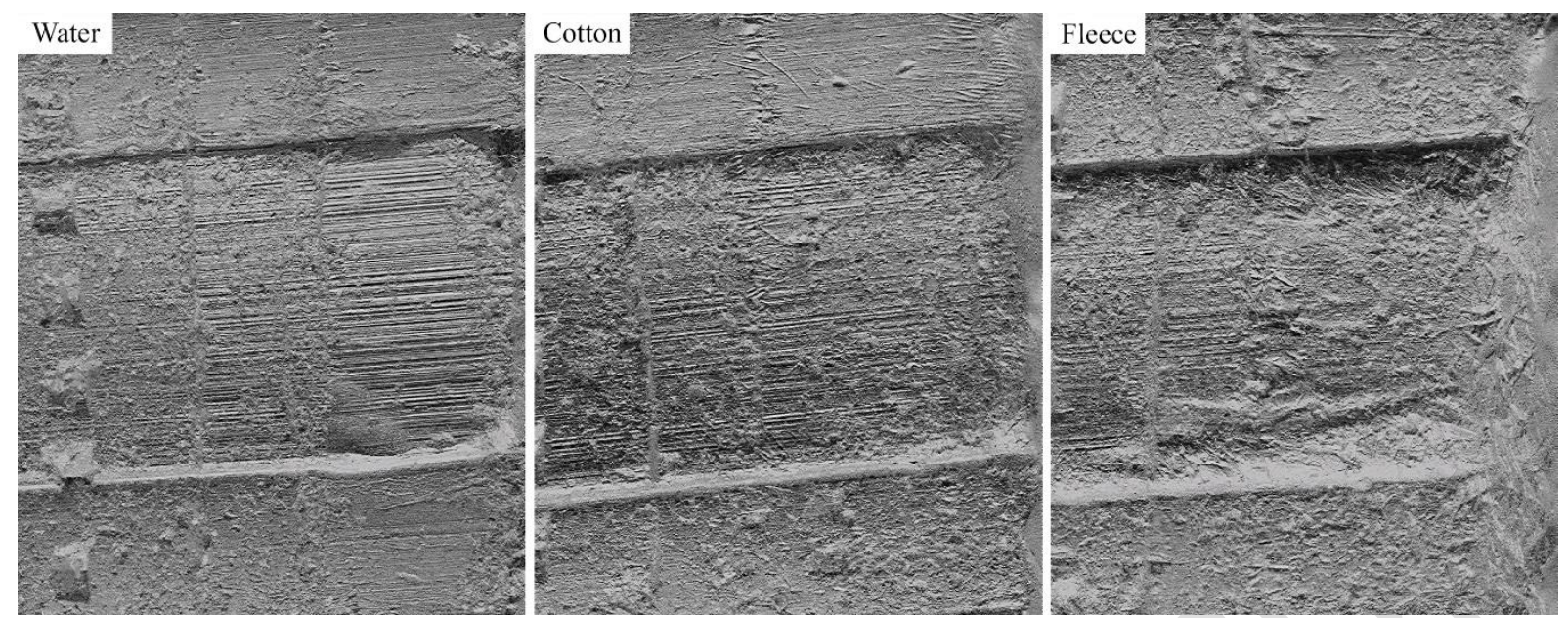

Figure 3. Marks on the surface of .22 Long Rifle bullets (test 1) with the three recovery systems.
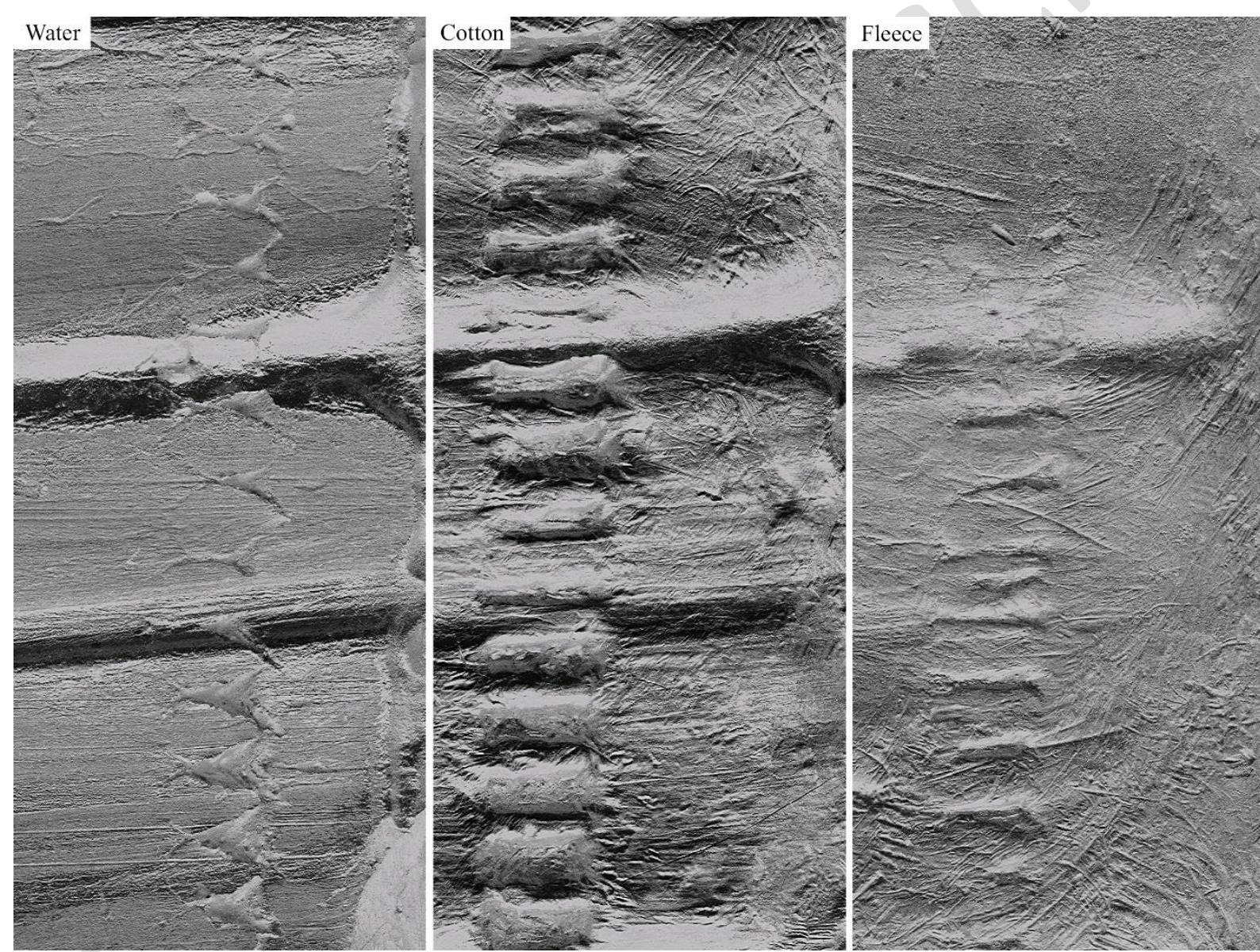

Figure 4. Marks on the surface of .357 Magnum Lead Flat Nose bullet (test 7) with the three recovery systems. 

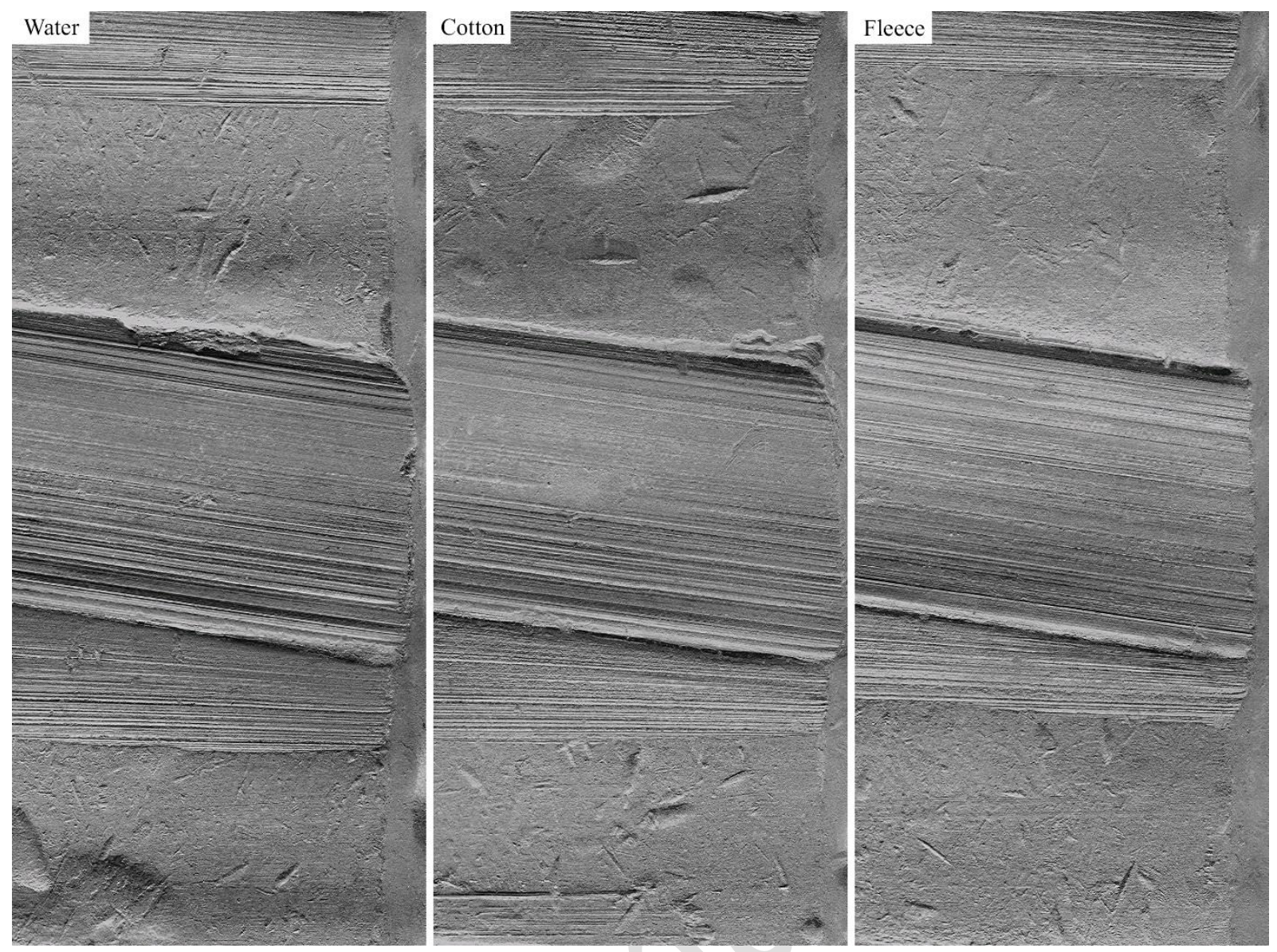

Figure 5. Marks on the surface of $9 \mathrm{~mm}$ Luger QD-PEP II (test 5) with the three recovery systems.

For the jacketed bullets (tests 3 and 8 ) and the deformation bullets (tests 5 and 6), the quality of the lands and grooves impressions is equivalent (Figures 5 and 6). Indeed, the border of the land impressions are well defined as well as the impressions of individual characteristics of the barrel (striae) inside the impressions. In the case of $9 \mathrm{~mm}$ Luger QD-PEP II (test 5), skid marks are also present with each system and their striation would be of sufficient quality to perform a comparison. While skid marks are less visible with the .45 ACP FMC bullet (test 8 ) with each recovery system, groove impressions are well defined between each land impressions. The only major difference between the three systems is with the $9 \mathrm{~mm}$ Luger SXT 9 Hollow point bullets (test 4) recovered with the water tank. The deformation and the damage sustained by these bullets makes their analysis difficult when using the Evofinder ${ }^{\circledR}$ system. While it would still be possible to study the marks left on the bullet's casing with a comparison macroscope, the recovery systems based on cotton or the Rubinum fleece are more efficient with these bullets. 


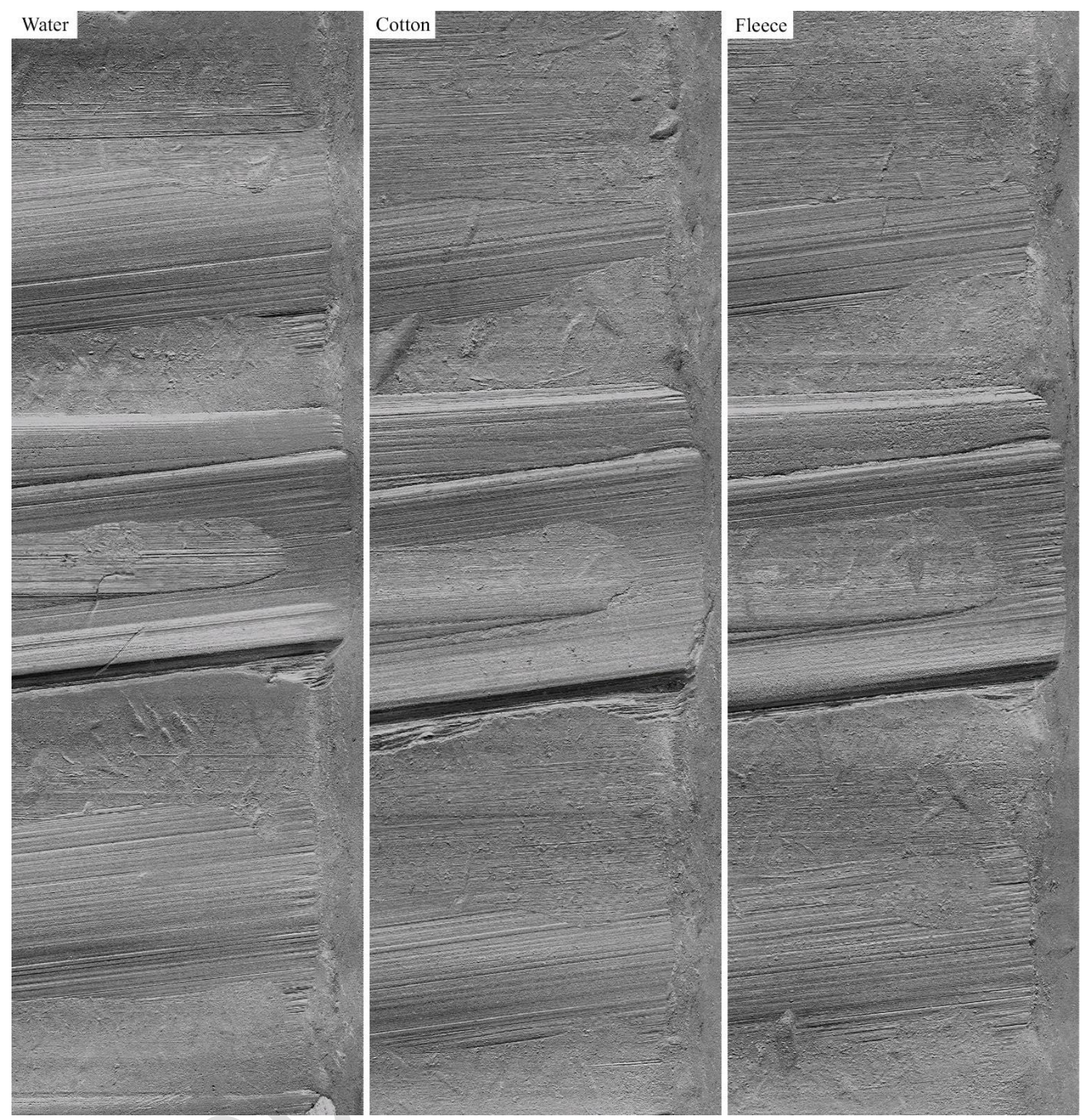

Figure 6. Marks on the surface of .45 ACP FMC bullet (test 8) with the three recovery systems..

\section{General discussion and conclusions}

While the water tank is an expensive device, it is also a simple system that allows to quickly recover fired bullets. Besides, the bullets recovered with this system do not require a cleaning procedure which might alter the quality of the marks on plated or lead bullets. However, the possibilities of this system in terms of calibres and types of bullets are limited respectively by the tank dimension's and the deformation or damages that occur when the bullet hits the water. Overall, the water tank is the more efficient system regarding the quality of the marks, but the two other systems - the cotton tube and the Rubinum fleece - allow to recover more types of projectile. The former is often considered as a cheap method, since it is sometimes composed of cotton waste. Its irregularities might be considered as a problematic in terms of reproducibility. On the other hand, the Rubinum fleece has the advantage to be more regular.

Defining the perfect system is a difficult task. So far, the existing recovery systems are complementary. Ideally a universal system would allow to stop bullets without damaging them while being adaptable to a wide range of calibres, including rifle bullets. In that sense, a system such as the Rubinum Engineering $\mathrm{GmbH}$ fleece is promising, as it appears to be more universal than the water tank which is limited to small calibres and difficult to use for certain types of bullets (e.g. hollow point, deformation bullets). Theoretically, it could be used to recover bullets fired with shoulder weapons. However, the question of the abrasive property of the fibres should be addressed to ensure a better visibility of the marks left by the barrel. Indeed, regarding plated or lead bullets, the effect is generally the same with every system: the land impressions are visible, but only a few marks would be suitable for an expertise. So far, the water tank would be recommended for this type of bullets as it appears less destructive than fibre-based systems. 
Among the perspectives of such results is a more thorough study of the impact of the recovery system on a firearm identification expertise process. Despite the fact that the production of reference bullets is essentially a case by case approach, such studies could be the first step towards guidelines regarding this important step of the forensic expertise. Especially with more challenging ammunition - such as rifle ammunition or other bullets prone to heavy fragmentation - for which alternative recovery systems are necessary. Then, simulating different forensic cases involving various recovery systems and bullet types would be a way to study the influence of these systems on the conclusion reached through an expertise process. In that sense, the score provided by the Evofinder® system would be a promising comparison metric to address these questions.

\section{References}

[1] Arnold, R and Gallant, J. A bullet recovery tank for under \$1500.00. AFTE Journal, 1988. 20(2): 168.

[2] Dragan, P and Miller, J. Atlanta Forensic Science Laboratory bullet recovery tank. AFTE Journal, 1996. 28(1): $1-2$.

[3] Miller, K. Description of water tank bullet recovery units at Missouri State Highway Patrol. AFTE Journal, 1971. 3(NL13): 18-22

[4] Moyer, F. Horizontal bullet recovery water chamber. AFTE Journal, 1977. 9(1): 32-38.

[5] Lee, F. Horizontal recovery tank. AFTE Journal, 1979. 11(2): 48.

[6] Cayton, J. Horizontal water recovery tank. AFTE Journal, 1974. 6(1): 23-24.

[7] Lansing, J and Seestrom, J. A cheap water recovery trap. AFTE Journal, 1975. 7(1): 54-56.

[8] Heard, B. A portable water recovery tank. AFTE Journal, 1980. 12(1): 42-43.

[9] Newquist, A. Test bullet recovery system. AFTE Journal, 1973. 5(1): 9.

[10] Molnar, S. A novel bullet recovery method. AFTE Journal, 1971. 3(NL16): 17.

[11] Lee, L. Bullet recovery in a six foot cotton box???? AFTE Journal, 1994. 26(4): 286.

[12] Haag, L. An inexpensive portable bullet recovery device. AFTE Journal, 1991. 23(1): 522-523.

[13] Sklorood, R. The use of dip-pak as a means of bullet recovery. AFTE Journal, 1971. 3(NL17): 17-20

[14] Ziegler, P. Bullet recovery using non-newtonian fluids. AFTE Journal, 1982. 14(3): 43-45

[15] Churchman, J. Test bullet recovery. Journal of the Canadian Society of Forensic Science, 1978. 11(2): 181.

[16] Shuherk, C, Investigation of effective forensic cleaning methods for bullet and cartridge case samples. 2015, Master's Thesis. Boston University, School of Medicine.

[17] Gallusser, A, ed. Traces d'armes à feu. Expertise des armes à feu et des éléments de munition dans l'investigation criminelle. 2nd edition ed. Collection Sciences forensiques. 2014, Presses Polytechniques et Universitaires Romandes: Lausanne.

[18] Wilhelm, R. ...und ACTION. Polizeipatrone ACTION 4 in 9 mm Luger. Deutsches Waffen-Journal, 2000. 5: 136-139.

[19] Wilhelm, R. Sinnvoll und gut. Die neue MEN-Polizeieinsatzpatrone QD-P.E.P. Deutsches Waffen-Journal, 2000. 1: 44-47. 